\title{
Dinâmica populacional de células mielóides durante o curso de inflamação crônica em camundongos C57BL/6 infectados com Toxoplasma gondii
}

\author{
Population dynamics of myeloid cells during the course of chronic inflammation \\ in C57 BL/6 mice infected with Toxoplasma gondii
}

\author{
Bárbara Cruz Tavares de Macedo Fernandes ${ }^{1}$ Maria Regina Reis Amendoeira ${ }^{2}$ \\ Ronald Bastos Freire ${ }^{1}$
}

\section{RESUMO}

Fagócitos mononucleares (Mø) e polimorfonucleares neutrófilos (PMN) foram analisados durante o curso da infecção por Toxoplasma gondii em camundongos C57 $B L / 6$, fêmeas, portadores de inflamações crônicas focais induzidas por material inerte. A dinâmica populacional de células mielóides dirigidas ao suporte inerte foi medida a partir do quarto dia após inoculação intraperitonial de 90100 cistos de T. gondii, ao longo de vinte dias, e comparada com o percentual relativo de leucócitos sangüíneos. Observou-se uma diminuição do percentual de PMN e um aumento significativo de Mø no sangue dos animais infectados. A infecção assintomática por T. gondii em camundongos resultou em um maior esforço do sistema mielóide na produção de células destinadas a combater focos inflamatórios, tornando-as menos aptas a responder adequadamente a diferentes fontes de infecção crônica. A mudança na maturidade e nas proporções normais de células mielóides indicou haver um bloqueio da extrusão de quimiocinas responsáveis pela atração quimiotática de PMN com comprometimento da resolução de focos inflamatórios durante infecções crônicas e assintomáticas por Toxoplasma gondii.

Palavras-chave:Toxoplasma gondii, células mielóides, infecção crônica, leucócitos.

\section{ABSTRACT}

Cells of the mononuclear and polymorphonuclear series were analyzed throughout the course of Toxoplasma gondii infections of $\mathrm{C} 57 \mathrm{BL} / 6$ female mice with chronic

\begin{abstract}
inflammatory foci. The animals were inoculated intraperitoneally with 90-100 parasitic cysts followed by subcutaneous implantation of cover glasses (after 4 days). The shift of leukocytes from the blood to the inflammatory focus, corresponding to a prolonged infiltration of myeloid cells, was measured in a time course of 20 days. A significant decline was observed in the mature polymorphonuclear cells in the blood and a concomitant development of a marked monocytosis. Infections with T. gondii in mice with chronic inflammatory foci resulted in dedication of the entire myeloid cells system to the generation of cells that were exported to combat the inflammation, which occurred in those places, and to the chronic infection itself. The shift in the normal proportions of cells and in cells of different degrees of maturity, suggesting that a blockade in the chemokines extruded to attract polimorphonuclear cells, might account to a large extent for the failure of immune responses commonly associated with Toxoplasma subclinical infections.
\end{abstract}

Key words: Toxoplasma gondii, myeloid cells, chronic infection, leukocytes.

\section{INTRODUÇÃO}

Toxoplasma gondii pertence ao Filo Apicomplexa, o qual inclui diversos agentes etiológicos de importância médica e veterinária. Este protozoário intracelular invade a célula hospedeira, evitando sua destruição pelo sistema imune. A célula infectada, entretanto, tem a capacidade de opor-se à invasão do patógeno iniciando sua própria morte, num

\footnotetext{
${ }^{1}$ Laboratório de Imunologia Molecular, Departamento de Biologia Animal (DBA), Instituto de Biologia (IB), Universidade Federal Rural do Rio de Janeiro (UFRRJ), BR 465, km7, 23851-970, Seropédica, RJ, Brasil. E-mail: rbfreire@ufrrj.br. Autor para correspondência.

${ }^{2}$ Laboratório de Imunomodulação, Departamento de Protozoologia, Instituto Oswaldo Cruz-FIOCRUZ, Rio de Janeiro, RJ, Brasil.
} 
processo chamado morte celular programada ou apoptose (VOLKER et al., 2001), no qual células apoptóticas são reconhecidas e fagocitadas por macrófagos. Este mecanismo de defesa do hospedeiro representa forte pressão seletiva sobre os parasitos, que desenvolvem estratégias para modular o programa apoptótico a seu favor. T. gondii faz parte do grupo de parasitos que inibem a apoptose das células hospedeiras, ganhando mais tempo para sua replicação (MOSS et al., 1999).

A fase aguda sintomática da toxoplasmose apresenta diversos indícios clínicos sobre sua evolução, tais como intensa resposta celular por linfócitos $\mathrm{T}$, presença de macrófagos ativados e aumento na produção de anticorpos específicos para determinantes antigênicos parasitários, principalmente contra as formas taquizoítas (NGUYEN et al., 1998).

No entanto, as infecções humanas por $\boldsymbol{T}$. gondii geralmente evoluem para a cronicidade, e os cistos tissulares tornam as formas parasitárias desapercebidas para o sistema imunitário do hospedeiro (DENNEY et al., 1999). Nesse caso, o sucesso do parasitismo crônico está relacionado ao controle parasitário da resposta inflamatória, o que determina a permanência silenciosa do parasita no organismo hospedeiro.

Este trabalho teve como objetivo a caracterização das variações nas populações de células inflamatórias durante o estabelecimento da infecção crônica por Toxoplasma gondii, assim como seus efeitos sobre o curso inflamatório crônico frente a um indutor inerte, que determina o tráfego leucocitário responsável pelo estabelecimento da imunidade no organismo hospedeiro.

\section{MATERIAL E MÉTODOS}

\section{Animais}

Foram utilizadas 42 fêmeas de camundongos da linhagem C57BL/6, pesando entre 12 e 15 gramas, mantidas em grupos de três animais por gaiola de poliestireno apropriada, com ração e água ad libitum.

Inoculação dos animais para os experimentos in vivo Utilizou-se a cepa ME49 de Toxoplasma gondii, cedida pelo Laboratório de Biologia Celular e Molecular de Parasitas do Instituto Oswaldo Cruz, RJ, e mantida através de passagens sucessivas em fêmeas de camundongos C57BL/6 com 30 dias de vida. O cérebro de um camundongo com 30 dias de infecção foi retirado, colocado em gral estéril, mantido sob refrigeração, adicionado de meio para cultivo de células na ausência de soro (Meio mínimo essencial TC 199 -
Difco, Inglaterra), cortado em pequenos pedaços, homogeneizado em micro-homogeneizador do tipo Potter (Elzividros, Brasil) e filtrado através de gaze dupla. O filtrado foi centrifugado à baixa rotação (600xg) para eliminação dos restos teciduais, e o sobrenadante acondicionado em frasco de centrifugação estéril (FREYRE, 1995). Foi retirada uma alíquota do sobrenadante, que foi adicionada de formol a $10 \%$ e diluída a 1:1000. Foram retirados $10 \mu \mathrm{l}$ do material diluído, e observado ao microscópio ótico comum (aumento de 400X) para identificação e contagem de cistos. Um grupo composto por vinte e um (21) camundongos foi inoculado intraperitonealmente com $0,1 \mathrm{ml}$ da suspensão, equivalente a aproximadamente 90 cistos tissulares.

Cultivo seletivo de células inflamatórias in vivo

Tanto os animais inoculados, como os do grupo controle, foram submetidos à cirurgia de implante de lamínulas, para a verificação do curso inflamatório diante da infecção por Toxoplasma gondii através do cultivo seletivo de células inflamatórias, realizado de acordo com a metodologia descrita por HERSKOWITZ et al. (1981). Os camundongos foram mantidos em jejum de alimentos sólidos durante 24 horas para serem anestesiados e submetidos à intervenção cirúrgica, que consistiu na abertura dorsal de uma bolsa, seguida do implante subcutâneo de lamínulas de vidro (18 X 18mm). A área do corte foi colapsada com grampos cirúrgicos. Os 42 animais submetidos à cirurgia foram mantidos em gaiolas individuais, para evitar injúrias no local da cirurgia. Grupos de três animais foram sacrificados por deslocamento cervical nos dias 4, 5, 6, 7, 10, 15 e 20 após a infecção e/ou o implante das lamínulas (DAI). Após o sacrifício, as lamínulas, contendo agregados de células inflamatórias aderidas, foram fixadas e coradas com o sistema comercial de coloração por hematoxilina-eosina (Panótico-Laborclin-Brasil), segundo indicações do fabricante. Simultaneamente à retirada das lamínulas implantadas, foram feitos esfregaços sangüíneos dos animais. As células presentes nas lamínulas e nos esfregaços sangüíneos dos animais dos grupos controle e infectado foram morfologicamente caracterizadas e quantificadas quanto ao número proporcional de polimorfonucleares neutrófilos (PMN) e de células do sistema fagocítico mononuclear (SFM) em microscópio Olympus CH30 (Japão).

Análise estatística dos resultados

As medidas de quantificação total, obtidas pela média da contagem das lâminas de cada grupo de 
três animais, foram analisadas através de ANOVA (DAWSON-SAUNDERS \& TRAPP, 1992). Utilizou-se também a comparação múltipla de DUNNET e todas as condições experimentais foram avaliadas em relação aos controles em cada DAI. Os resultados percentuais não transformados foram comparativamente analisados através do teste de comparações múltiplas de DUNN (DAWSON-SAUNDERS \& TRAPP, 1992). Em ambos os casos, houve concordância para a significância dos resultados obtidos. A comparação simples entre as condições controle e experimental, para as quais foram determinadas variâncias distintas, foi realizada através de teste-t binomial de Welch.

\section{RESULTADOS E DISCUSSÃO}

No presente trabalho, avaliou-se a dinâmica das células mielóides no curso de infecções crônicas por Toxoplasma gondii através da observação da transferência ativa de células do sangue para lamínulas implantadas. Distinguiram-se as populações de células inflamatórias que mantinham a capacidade de mobilizarem-se para o corpo estranho. A capacidade de modulação dos mediadores responsáveis pela sinalização leucocitária por T. gondii está relacionada ao fato de que o parasito pode, simultaneamente, suprimir e induzir a resposta imune inata do hospedeiro, de modo a sobreviver durante o maior tempo possível, sem ser eliminado. As células dendríticas, os neutrófilos (PMN) e os macrófagos (M $\phi)$, importantes fontes de interleucina 12 (IL-12), são estimulados por T. gondii por dois mecanismos: através da proteína MyD88, provavelmente relacionada a receptores similares ao receptor Toll, e, mais freqüentemente, através da estimulação de receptores CCR5 pela citofilina parasitária (DENNEY et al., 1999). Contrariando essas atividades pró-inflamatórias, $\boldsymbol{T}$. gondii apresenta vários mecanismos para regular negativamente a imunidade durante o curso das infecções crônicas assintomáticas. Nesse caso, a infecção intracelular causa um bloqueio nos mecanismos de sinalização de $\mathrm{M} \phi$, com conseqüente redução da produção de IL-12 e TNF- $\alpha$. O parasito também inibe receptores do MHC, resultando em redução dos níveis de interferon gama (IFN- $\gamma$ ) e induz a resistência à apoptose, através da inibição das caspases (VOLKER et al., 2001; HERZOG SOARES \& FREIRE, 2004).

A estratificação dos percentuais relativos de células do SFM dirigidas ao foco inflamatório inerte permitiu estabelecer diferenças significativas entre animais infectados e não infectados, com base no percentual médio de $\mathrm{M} \phi$ aderidos às lamínulas (Figura
1). A indução da diferenciação específica de células do SFM, tal como observado por GUIMARÃES (2002), forneceu um perfil evolutivo e dinâmico do processo inflamatório crônico induzido por material inerte, frente à infecção por T. gondii. O número de células mielóides aderidas às lamínulas, quantificadas microscopicamente, foi sempre superior nos hospedeiros infectados, quando comparados com os respectivos controles, provavelmente em função da necessidade do parasito em utilizar células do SFM para o estabelecimento de cistos e de formas de resistência à resposta imunitária.

Em ambos os grupos (parasitados e controles), foram identificados infiltrados inflamatórios restritos à presença de PMN e células do SFM (Figuras $2 \mathrm{~A}$ e 2B). Os $\mathrm{M} \phi$ fundiram-se ao longo do curso experimental, originando células gigantes multinucleadas (Figura IIC) que, por sua vez, transformaram-se em células epitelióides (Figura IID) que desapareceram, dando lugar a novas populações durante a evolução do processo inflamatório crônico induzido pelo corpo estranho não eliminado durante o estágio inflamatório inicial.

Nos animais controles, durante o 4 ${ }^{\circ} \mathrm{DAI}$, foram detectados PMN (4,74 $\pm 1,32$ x $10^{5}$ células $\left.\mathrm{cm}^{-2}\right)$ e monócitos $\left(3,62 \pm 0,67 \times 10^{5}\right.$ células $\left.\mathrm{cm}^{-2}\right)$ em grandes proporções, sendo que essas populações mostraram-

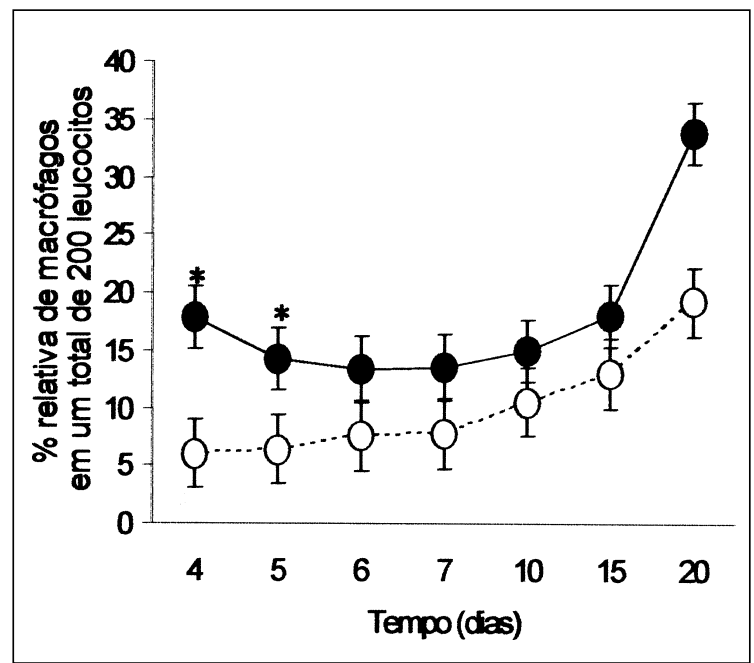

Figura 1 - Média percentual de macrófagos em esfregaços sangüíneos de camundongos C57BL/6, ao longo de vinte dias de infecção com a cepa ME-49 de Toxoplasma gondii (figuras cheias) em relação a animais não infectados (figuras vazias). Os dados representam uma média da contagem total de três lâminas por grupo experimental em cada dia de observação. Os asteriscos assinalam diferenças estatisticamente significativas $(p<0,01)$.

Ciência Rural, v.35, n.6, nov-dez, 2005. 


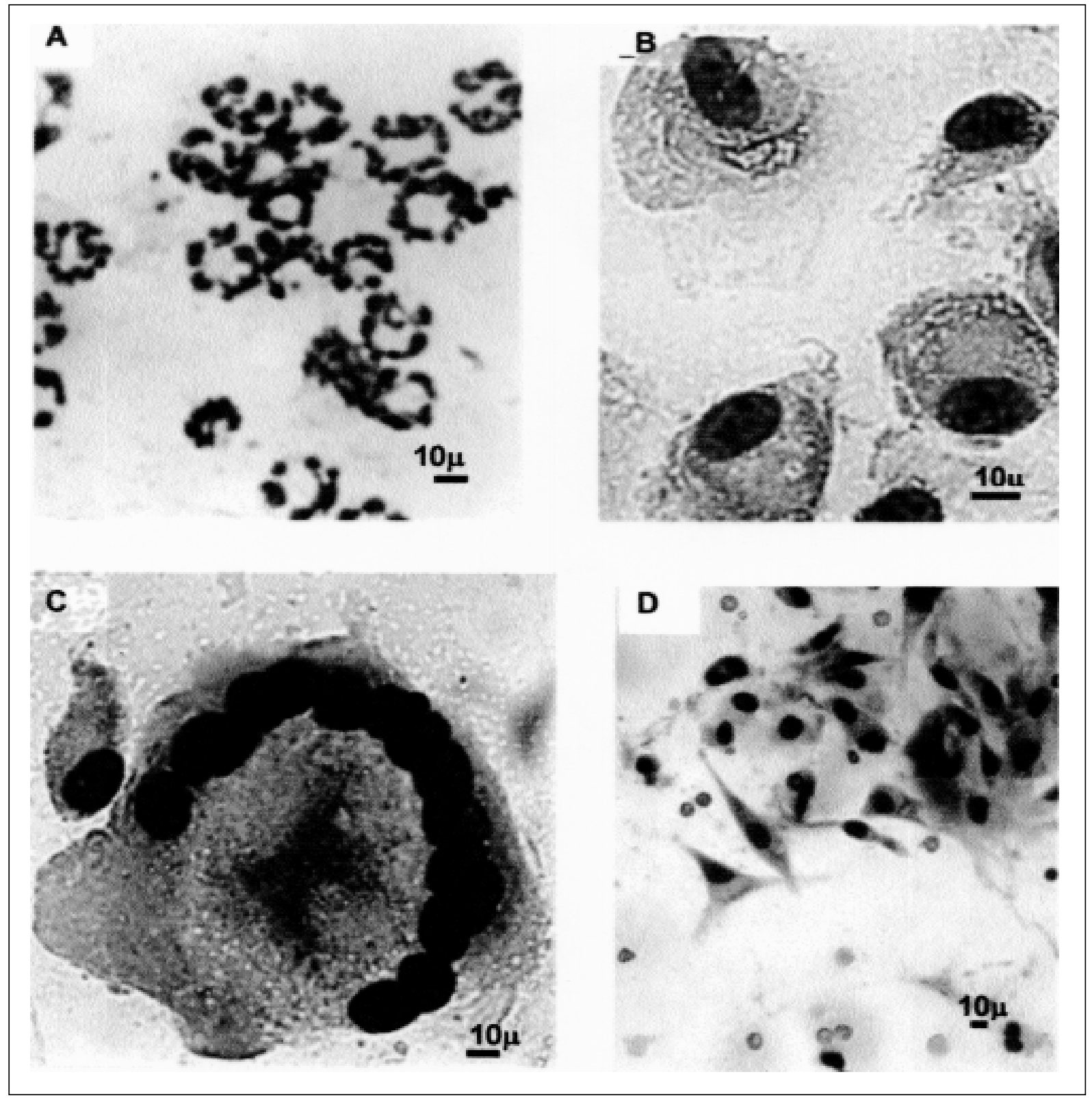

Figura 2 - Fotomicrografias de células inflamatórias em lamínulas implantadas no dorso de camundongos C57BL/6 observadas ao microscópio ótico sob imersão: (A) Polimorfonucleares Neutrófilos observados após 24 horas de implantação das lamínulas; (B) Macrófagos observados ao 4 dia após infecção (DAI); (C) Célula gigante multinucleada observada ao 15ํㅡㄹㄱ; (D) Células epitelióides observadas ao 20ํㅡㄹ. Preparações fixadas pelo Panótico e coradas por hematoxilina-eosina.

se gradativamente alteradas nos dias subsequentes. No $7^{\circ}$ DAI, observou-se uma média de $1,26 \pm 0,56 \times 10^{2}$ PMN cm${ }^{-2}, 5,77 \pm 0,43 \times 10^{6}$ macrófagos $\mathrm{cm}^{-2}$ e 3,95 \pm $0,81 \times 10^{3}$ células gigantes multinucleadas $\mathrm{cm}^{-2}$. Esses dois últimos tipos celulares foram especialmente observados a partir do $5^{\circ} \mathrm{DAI}$, perfazendo um total de $1,34 \pm 0,57$ x $10^{6}$ células do SFM/ $\mathrm{cm}^{-2}$. As observações realizadas no $10^{\circ}$ e no $20^{\circ}$ DAI evidenciaram a média de 0,32 $\pm 0,11$ x $10^{2}$ células epitelióides $\mathrm{cm}^{-2}$ e 2,01 \pm
0,31 x $10^{3}$ células epitelióides $\mathrm{cm}^{-2}$, respectivamente, acompanhadas de um número estável de células do SFM e de PMN (Figura 3).

Nos indivíduos infectados por T. gondii, observaram-se alterações nas proporções de todos os tipos de células mielóides durante o curso experimental (Figura 3). Nesses animais, no $4^{\circ} \mathrm{DAI}$, foi observado aumento equivalente a 1,8 vezes $(p=0,011)$ no número de PMN em relação ao grupo controle, 

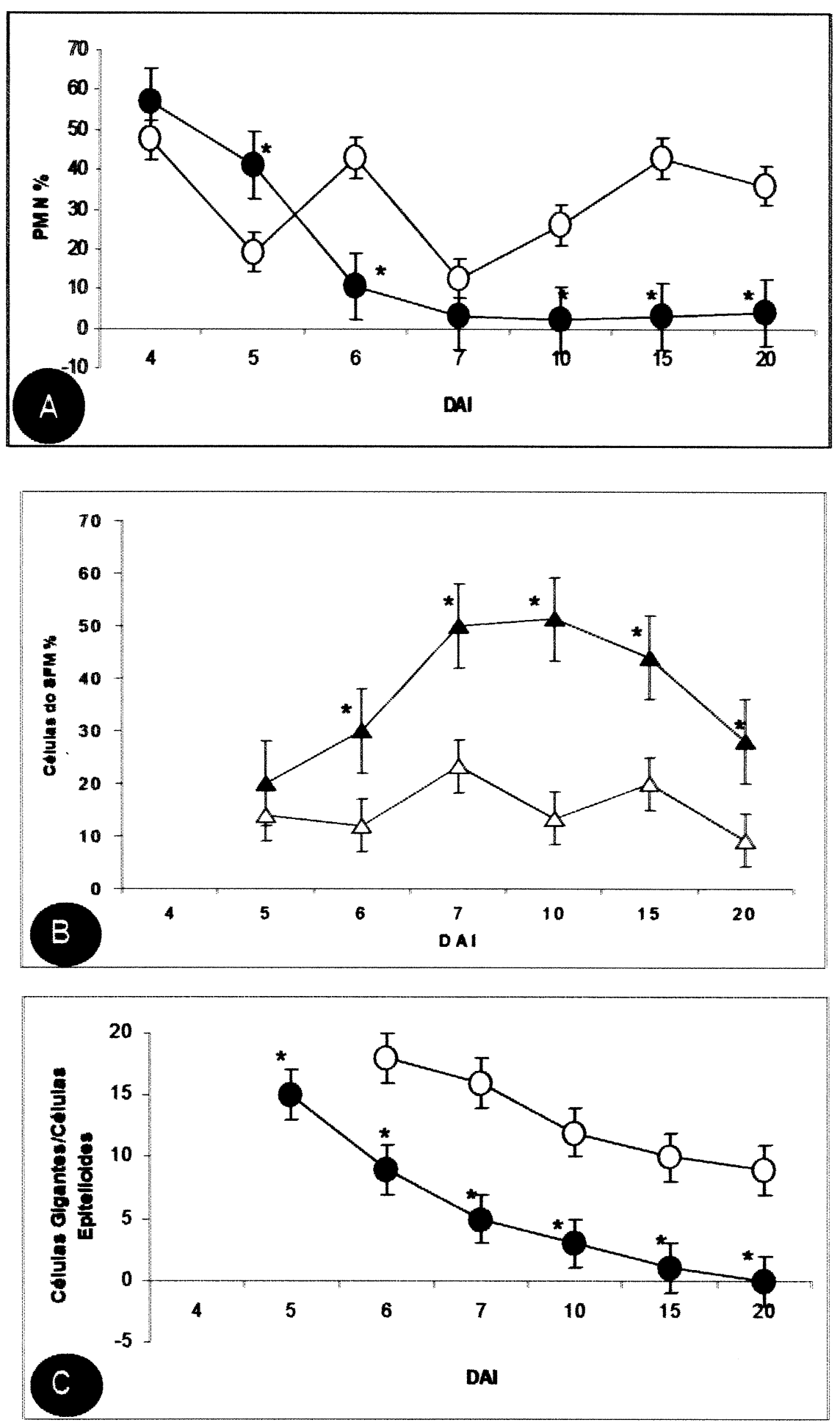

Figura 3 - Distribuição relativa de leucócitos aderidos às lamínulas implantadas no dorso de camundongos C57BL/6, nos animais controle (figuras vazias) e nos animais infectados com Toxoplasma gondii (figuras cheias). (A) Percentual médio de polimorfonucleares neutrófilos (PMN). (B) Percentual médio de células do sistema fagocítico mononuclear (SFM). (C) Razão entre células gigantes e epitelióides. Os asteriscos representam diferenças estatisticamente significativas $(\mathrm{P}<0,01)$. 
decrescendo a partir do $6^{\circ} \mathrm{DAI}$, quando o percentual quantificado de PMN mostrou-se bastante inferior ao do grupo controle (Figura 3A). No grupo controle, os PMN tenderam a desaparecer entre 12 e 24 horas após o implante das lamínulas, sendo substituídos por novos neutrófilos, de maneira linear, devido à sua pequena vida média e à realimentação do foco inflamatório pelo suporte inerte não degradável (lamínulas de vidro). Esse aumento do número de PMN está relacionado à eliminação de mediadores (IL-8) que ocorre nos processos inflamatórios agudos (HERZOG- SOARES \& FREIRE, 2004). Desse modo, o aumento relativo de infiltrados de PMN nos estágios iniciais em indivíduos infectados foi concordante com NGUYEN et al. (1998) e DENNEY et al. (1999), que verificaram serem a inibição de CCR5 e de quimiocinas os elementos afetados na orientação do curso infeccioso para a forma crônica da doença. Assim, pode-se depreender que a diminuição do número relativo de PMN nos infiltrados inflamatórios, assim como a contagem relativa das células nos esfregaços sangüíneos com intensa monocitose, associada à crescente neutropenia, decorreu de interrupções na mediação quimiotática de atração de PMN por macrófagos, os quais estariam com seu metabolismo celular comprometido pelo parasitismo (CERAVOLO et al., 1999, DENNEY et al., 1999, VOLKER et al., 2001).

O número relativo de células do SFM permaneceu estável até o $20^{\circ}$ dia de experimentação (DAI), tanto nos animais controles como nos infectados, quando foram quantificados $6,01 \pm 1,26 \times 10^{6}$ macrófagos $\mathrm{cm}^{-2}$. Observou-se que os animais infectados apresentaram percentuais de células do SFM aderidas às lamínulas significativamente superiores aos controles a partir do 6음 DAI (Figura 3B).

Em ambos os grupos de animais, houve uma distribuição oscilante no número de monócitos aderidos às lamínulas, permanecendo numericamente aumentados até o 5oㅡㄹ DAI, e tendendo à diminuição à medida que o número de $\mathrm{M} \phi$ aumentou. Nos animais infectados, observou-se um aumento prematuro no número percentual de células gigantes multinucleadas e de células epitelióides que, nesse caso, mostraramse presentes a partir do 5을 DAI (Figura 3C), mantendose proporcionalmente aumentadas em relação ao controle durante todo o período experimental. Detectou-se uma média de 1,84 \pm 0,19 x 103 células epitelióides $\mathrm{cm}^{-2}$ ao $20^{\circ}$ DAI nos animais controles, e de 9,5 $\pm 0,08 \times 104$ células epitelióides $\mathrm{cm}^{-2}$, no mesmo período, nos animais infectados. A permanência de células epitelióides nos animais infectados sem uma conseqüente atração quimiotática de novas células fagocíticas, determinou a degeneração das mesmas e a conseqüente presença de restos celulares típicos de infiltrados necróticos, de forma concordante com a literatura, e se sugeriu que o parasito inibia enzimas relativas ao desencadeamento de apoptose celular, de modo a favorecer a manutenção do parasitismo intracelular (VOLKER, 2001, DENEY et al., 1999).

O aumento na proporção de células do SFM, observado no presente experimento, a despeito de evidenciar a reposição de macrófagos para os focos inflamatórios inertes, tanto nos animais controle como nos infectados, apresentou diferenças representativas entre os grupos. Nos animais infectados, nenhum dos fagócitos aderidos às lamínulas apresentou parasitismo intracelular. De outro modo, foram observados inúmeros macrófagos parasitados no sangue circulante desses mesmos animais, evidenciando as alterações do tráfego leucocitário devidas à paralisação metabólica de células fagocitárias infectadas por T. gondii (SILVA et al., 1998, CERAVOLO et al., 1999, DENEY et al 1999, HERZOG SOARES \& FREIRE, 2004).

A despeito de serem aparentemente semelhantes, o perfil de células do SFM aderidas às lamínulas evidenciou uma tendência divergente no que diz respeito à modalidade de morte celular entre os animais controle e infectados. O aumento numérico de células gigantes multinucleadas no grupo controle seguiu a tendência clássica de resposta inflamatória crônica a materiais inertes não digeridos. Houve dificuldade no processamento do alvo (lamínula de vidro), tendo como conseqüência a fusão de células fagocitárias que se tornam multinucleadas, sem que tenha ocorrido policariogênese mitótica, indicando a continuidade do ciclo celular, cuja tendência foi o envelhecimento e a desagregação, com diferenciação de células gigantes multinucleadas em células epitelióides que, por sua vez, desapareceram, dando lugar a novos infiltrados leucocitários constituídos por PMN e Mø. Nesse contexto, os fragmentos celulares gerados apresentam atividade metabólica e são fagocitados por outras células mielóides, determinando, dessa forma, o desaparecimento natural das células apoptóticas, que são elementos de atração e realimentação do foco inflamatório, na ausência de danos perceptíveis (ABBAS et al, 2000). Nos animais infectados, a distribuição de células dirigidas ao foco inflamatório foi sugestiva de que morte celular tenha ocorrido por necrose celular, ao invés de apoptose, corroborando com dados anteriores obtidos em estudos da inibição dos processos de apoptose por protozoários intracelulares, como estratégia de preservação de seus sistemas hospedeiros (VOLKER et al., 2001). Observaram-se diminuição relativa de células gigantes, 
associada ao aumento progressivo da quantidade de células epitelióides (Figura IIIC), que permaneceram presentes e degeneraram, de forma irreversível, sem que houvesse atração quimiotática significativa de novas células mielóides no foco inflamatório. A ausência de PMN, com a presença de um número crescente de células degeneradas confirmaram a influência negativa do parasitismo intracelular crônico sobre os processos de realimentação do foco inflamatório, corroborando com estudos sobre a leucopenia induzida por infecções por T. gondii (BLISS et al., 2001).

\section{CONCLUSÕES}

A modulação negativa dos mediadores próinflamatórios e a inibição de enzimas intracelulares são as principais estratégias utilizadas por Toxoplasma gondii na definição do parasitismo assintomático em hospedeiros intermediários. Por ser considerado um parasito oportunista de grande ocorrência para diferentes espécies animais e para o homem, a sua capacidade de alterar o metabolismo, a função e a mediação de células inflamatórias, muitas vezes, é subestimada, uma vez que oferece condições para a instalação de outros agentes infecciosos e altera o curso da resposta imunitária inata, comprometendo a imunidade, de grande relevância para neonatos. Por conta disso, é necessário que se realizem estudos para melhor compreensão das bases celulares e moleculares da imunologia das infecções por Toxoplasma, assim como seu papel na imputação dos processos de sinalização das células hospedeiras.

\section{AGRADECIMENTOS}

Os autores agradecem aos bolsistas de iniciação científica Paulo Vitor da Silva e Souza, Leonardo Rosadas e Felipe Baggio Vianna. Este trabalho teve apoio da CAPES, CNPq e FAPERJ, e foi aprovado pela Comissão de Ética e Biossegurança da Universidade Federal Rural do Rio de Janeiro.

\section{REFERÊNCIAS}

ABBAS, A.K. et al. Cellular and molecular Immunology. Philadelphia: Saunders, 2000. 553p.

BLISS, S.K. et al. Neutrophil depletion during Toxoplasma gondii infection leads to impaired immunity and lethal systemic pathology. Infection and Immunity, v.69, n.8, p.4898-4905, 2001.

CERAVOLO, I.P. et al. Replication of Toxoplasma gondii, but not Trypanosoma cruzi, is regulated in human fibroblasts activated with gamma interferon: requirement of a functional JAK/STAT pathway. Infection and Immunity, v.67, n.5, p.2233-2240, 1999.

DAWSON-SAUNDERS, B.; TRAPP, R.G. Basic and clinical biostatistics. Norwalk, Connecticut: Appleton \& Lange, 1992. 344p.

DENNEY, C.F et al. Chemokine secretion of human cells in response to Toxoplasma gondii infection. Infection and Immunity, v.67, n.4, p.1547-1552, 1999.

FREYRE, A. Separation of Toxoplasma cysts from brain tissue and liberation of viable bradyzoites. Journal of Parasitology, v.81, n.1, p.1008-1010, 1995.

GUIMARÃES, E.V. Citoquímica ultra-estrutural e endocitose em cistos tissulares de Toxoplasma gondii e aspectos da cistogênese na célula muscular esquelética in vitro. 2002. 126f. Dissertação (Mestrado em Biologia Parasitária) - Curso de Pós-graduação em Biologia Parasitária, Fundação Instituto Oswaldo Cruz, Rio de Janeiro.

HERZOG-SOARES, J.D.A.; FREIRE, R.B. Effect of citrinin and in association with aflatoxin $\mathrm{B}_{1}$ on the infectivity and proliferation of Toxoplasma gondii in vitro. Braz J Infect Dis, v.8, n.1, p.101-108, 2004,

HERSKOWITZ, H.T. et al. Manual of macrophage methodology. USA: Paulnock, 1981. 138p.

MOSS, J.E. et al. The regulation of apoptosis by microbial pathogens. International Review of Cytology, v.187, n.3, p.203-259, 1999.

NGUYEN, T.D. et al. Acute and chronic phases of Toxoplasma gondii infection in mice modulate the host immune responses. Infection and Immunity, v.66, n.6, p.2991-2995, 1998.

SILVA, N.M. et al. Expression of Toxoplasma gondii-specific heat shock protein 70 during in vivo conversion of bradyzoites to tachyzoites. Infection and Immunity, v.66, n.8, p.39593963, 1998.

VOLKER, T.H. et al. Inhibition of apoptosis by intracellular protozoan parasites. International Journal for Parasitology, v.31, n.1, p.1166-1176, 2001. 